\title{
Economic security of the university in the context of the pandemic: influence of conservative and creative factors
}

\author{
Elena Dvoryadkina, and Kamal Guseynly* \\ Ural State University of Economics, st. March 8, 62/45, 620144 Ekaterinburg, Russia
}

\begin{abstract}
This article is devoted by the authors to the study of conservative and creative factors that affect the economic security of the organization of higher education in the post-pandemic period. The author's classification of conservative and creative factors is proposed on the basis of the author's approach to assessing the level of economic security of the organization of higher education. The assessment of the level of economic security of the Ural State University of Economics in the period for 2016-2020 was carried out, during which each indicator was analyzed separately, in particular, the level of their influence. According to the results of the study, it can be determined that throughout the entire period of the study, USUE's economic security was largely influenced by creative factors, but in 2020, USUE minimized the influence of most creative and conservative factors.
\end{abstract}

\section{Introduction}

The university, as a social institution, is affected by various processes, which has a direct impact on its economic security. The economic security of the higher education organization is the state of security of the subjects of educational activity (various types of resources of the organization) intended for the implementation as the main goal of educational activities in the educational programs of higher education and scientific activities, based on ensuring the effectiveness of the educational organization in the context of the factors affecting it.

The past year 2020 has made adjustments in all spheres of life of the population and economic processes in Russia. The director of the Accounting Chamber of the Russian Federation in his scientific work on the impact of coronavirus on the life of the population in 2021 notes: "The COVID-19 pandemic has dramatically changed the situation in the field of education in all countries of the world. As in most areas of the economy, activity in education was frozen for a while" [1].

In this regard, it becomes important to comply with the epidemiological requirements associated with the new coronavirus infection. According to the research conducted by the Higher School of Economics, five main challenges are expected for higher education organizations [2].

\footnotetext{
*Corresponding author: guseinli_kamal@mail.ru
} 
1. The quality of educational programs for future applicants and students is expected to deteriorate, which may lead to an increase in the social differentiation of different groups of students.

2. Due to unplanned and necessary financing of other spheres of life of the population, subsidies to higher education organizations are reduced, and therefore mass layoffs of researchers are possible. According to a study by the International Monetary Fund, in the next six years, the world will not be able to achieve the level of education funding that will be equal to the level of 2018 [4].

3. The emergence of a barrier between students and teachers in the process of obtaining educational programs. This may be caused by a lack of technical tools on both sides.

4. Unemployment among graduates. This risk is possible due to the new format of training, in connection with which there will be a lack of communication skills among graduates, the manifestation of initiative, etc.The conditions for obtaining educational programs are changing, but not the requirements of employers.

5. Changes in the market conditions of the principles and approaches to obtaining educational programs. Smooth shift of traditional conservative forms of the educational process.

As we found out earlier, the economic security of the organization of higher education is under the influence of various processes, phenomena and factors. The coronavirus pandemic contributes to the emergence of new factors that change the situation in modern higher education, and as a result, the economic security of the university is under their influence.

\section{Materials and Methods}

The current state, development prospects, efficiency and economic security of non-profit organizations, educational organizations and organizations of higher education are in the focus of attention of modern scientists. Among them, attention was paid to the development of universities: E. N. Levashov [9], I. M. Ilyinsky [10], M. A. Vinokurov [11], M. P. Astafyeva, O. A. Zyateva, I. V. Peshkova, E. A. Pitukhin [12], E. V. Mikhailin, A.V. Grachev [14], A.V. Taraskina, S. N. Obukhova, S. V. Zolotova [15]

It can be determined that the achievement of results, the activities of educational programs and the scientific activities of the organization of higher education are influenced by various objects, processes or phenomena. And only by learning to control the factors and predict the possible consequences, it becomes possible to ensure a high level of economic security.

In modern conditions, which in 2020 were complicated by post-pandemic realities, there is a transformation of the level of influence of factors, therefore, along with traditional conservative factors, new (let's call them creative) factors appear that influence the effectiveness of the organization of higher education in the system of ensuring economic security.

Conservative factors are objects, processes or phenomena that have formed in the longterm retrospect and are traditional for the organization of higher education. Creative factors are objects, processes or phenomena that have formed in the short-term retrospect and are innovative for the organization of higher education and are associated with new types of activities for it.

To assess the economic security of the organization of higher education, the authors propose a methodology, which is tested by the analysis in different directions. Based on the author's approach to the classification of factors, the indicators can be divided into 2 groups: those that characterize creative factors and those that reflect conservative factors (Fig. 1). 


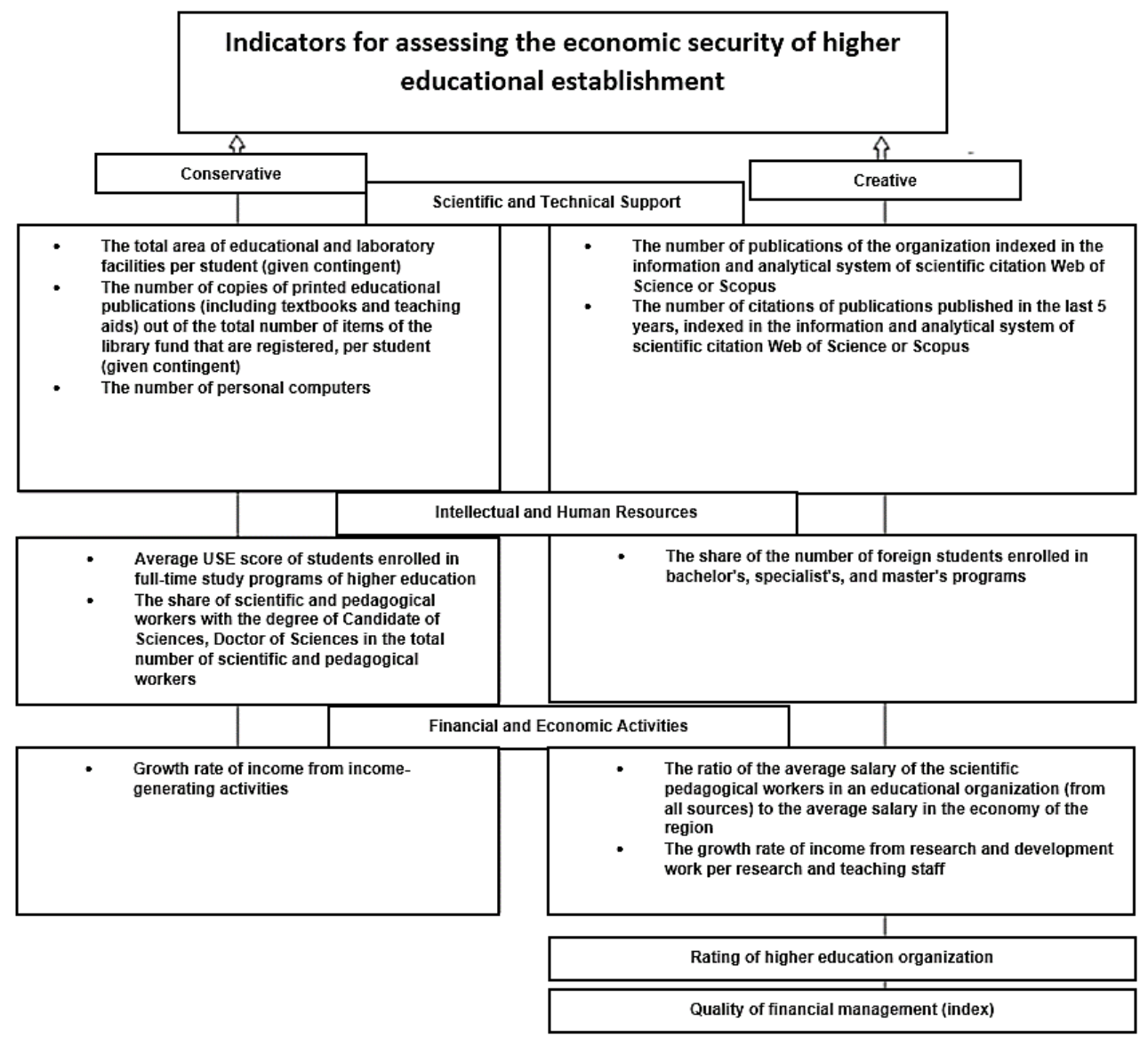

Fig. 1. Indicators for assessing the economic security of higher education organizations with a classification into conservative and creative

Having given the indicators that characterize the economic security of the organization of higher education, it is necessary to determine their threshold values and the number of points within the framework of the author's assessment methodology. For certain indicators, the average number in mathematical statistics will be used as a threshold value - the median value, since it will allow you to determine the average value for the industry, or among universities in this region for the current year. The threshold values will be determined based on the "traffic light" method, where 50 is the median value; from 0 to 32 - "red zone" $=0$ points; from 33 to 66 - "yellow zone" = 5 points; from 64 to 100 - "green zone" $=10$ points. Among these indicators: the total area of educational and laboratory premises per student (the specified contingent); the number of copies of printed educational publications (including textbooks and teaching aids) from the total number of storage units of the library fund, registered, per student (the specified contingent); the share of NPR, having the degree of Candidate of science, Doctor of science in the total number of NPR; the number of personal computers.

For the next group of indicators will be used portable values used in the method of the Ministry of science and higher sample, while, according to the author's type, we offer you the redistribution of points, where in addition to the run of exhibits, has more calls than the number of points than a special performance of readings.: 
the composition is perfectly paced study and development work in the distribution is not a simple pedagogical workflow: more than $1 \%$ - 0 points; $1-5 \%$ - 3 points; $6-10 \%$ - 6 points; $11-15 \%-9$ points; $16 \%$ and more than 12 points;

to allow sets of environment coercing interior: more than $1 \%-0$ points; $1-5 \%-3$ points; 6-10\% - 6 points; $11-15 \%-9$ points; $16-20 \%-12$ points; $21 \%$ or more- 15 points

with each swing of the financial Manager (index): low value - 0 points; the average value of 10 points; the highest value -20 points;

the ratio of harmful NPR platinum in a model organization (from all sources) to harmful payment in the economy of regulation: more than $35 \%-0$ points; $35-69 \%-5$ points; 70 $104 \%$ - 10 points; $105-139 \%$ - 15 points; $140-174 \%-20 \% ; 175 \%$ or more- 25 points.

For all other indicators, it is proposed to equalize the number of points: $0,5,10$ :

the average score of the Unified State Exam of students who have turned down full-time education in higher education programs. According to the degree of compliance with the indicator of the organization of higher education, points are awarded at 3 levels: if less than $60-0$ points; $60-65-10$ points; 66 and more- 15 points.

the number of publications of the organization indexed in the information and analytical system of scientific citation Web of Science or Scopus: less than 20-0 points; 20-100-5 points; 101 and more-10 points.

the number of citations of publications published over the past 5 years, indexed in the information and analytical system of scientific citation Web of Science or Scopus: less than 6-0 points; 6-500-5 points; 501 and more-10 points.

the proportion of the number of foreign students enrolled in bachelor's, specialist's, or master's programs in the total number of students: if less than $2 \%-0$ points; $2 \%-8 \%-5$ points; $9 \%$ or more-10 points.

The extreme indicator of the assessment of the economic security of the organization of higher education is the rating of the university. The rating of the best universities in Developing Europe and Central Asia will be the basis for the assessment. The distribution of points will be as follows: place below 400-0 points; place 400-301-2 points; place $300-201$ -4 points; place $200-101-6$ points; place $100-51-8$ points; place $50-1-10$ points.

When analyzing the values of indicators and their impact on the economic security of the organization of higher education, it is necessary to take into account the belonging of indicators to conservative or creative factors, in order to understand the influence of which has a greater impact. After that, it is necessary to assess the level of economic security of the organization of higher education, by calculating the total number of points scored. The maximum number of points is 167. Classes of economic security (specific weight of points) are proposed to be classified as follows: 5 th class- $0-30 \%$; 4th class-31-50\%; 3rd grade -51 70 points; 2 nd grade- $71-85 \%$; 1 st grade- $86-100 \%$.

\section{Results and Discussion}

Ural State University of Economics (USUE) is one of the leading higher educational institutions in the Sverdlovsk region and is one of the TOP 100 Russian higher education organizations[13]. Thus, ensuring economic security is the key to USUE's economic growth. We will analyze the level of economic security of USUE according to the author's approach (Table 1).

Conducting this assessment of economic security will allow us to determine whether conservative or creative factors have a greater impact on the Ural State University of Economics during the pandemic. We will present the results of the calculation over a period of 5 years and conduct an analysis. 
Table 1. Values of USUE economic security indicators for 2016-2020

\begin{tabular}{|c|c|c|c|c|c|c|}
\hline \multirow{2}{*}{ № } & \multirow{2}{*}{ Indicator } & \multicolumn{5}{|c|}{ Year } \\
\hline & & 2016 & 2017 & 2018 & 2019 & 2020 \\
\hline \multicolumn{7}{|c|}{ Scientific and technical support } \\
\hline 1 & $\begin{array}{l}\text { The total area of educational and laboratory } \\
\text { facilities per student (given contingent), } \mathrm{m} 2\end{array}$ & 7,24 & 6,51 & 6,29 & 6,65 & 6,67 \\
\hline 2 & $\begin{array}{l}\text { The number of copies of printed educational } \\
\text { publications (including textbooks and } \\
\text { teaching aids) out of the total number of } \\
\text { items of the library fund that are registered, } \\
\text { per student (given contingent), units }\end{array}$ & 137,26 & 126,37 & 118,69 & 124,16 & 126,62 \\
\hline 3 & $\begin{array}{l}\text { The number of personal computers per } \\
\text { student (given contingent), units. }\end{array}$ & 0,31 & 0,32 & 0,35 & 0,33 & 0,33 \\
\hline 4 & $\begin{array}{l}\text { The number of publications of the } \\
\text { organization indexed in the information and } \\
\text { analytical system of scientific citation Web } \\
\text { of Science or Scopus }\end{array}$ & 108 & 199 & 260 & 386 & 293 \\
\hline 5 & $\begin{array}{l}\text { The number of citations of publications } \\
\text { published in the last } 5 \text { years, indexed in the } \\
\text { information and analytical system of } \\
\text { scientific citation Web of Science or Scopus }\end{array}$ & 264 & 371 & 568 & 991 & 1017 \\
\hline \multicolumn{7}{|c|}{ Intellectual and human resources } \\
\hline 6 & $\begin{array}{l}\text { Average USE score of students enrolled in } \\
\text { full-time study programs of higher education }\end{array}$ & 60,66 & 61,06 & 62,94 & 63,8 & 66,0 \\
\hline 7 & $\begin{array}{l}\text { The share of scientific and pedagogical } \\
\text { workers with the degree of Candidate of } \\
\text { Sciences, Doctor of Sciences in the total } \\
\text { number of SPW, \% }\end{array}$ & 60,37 & 70,05 & 73,73 & 75,11 & 76,32 \\
\hline 8 & $\begin{array}{l}\text { The share of the number of foreign students } \\
\text { enrolled in bachelor's, specialist's, and } \\
\text { master's programs, \% }\end{array}$ & 1,98 & 1,94 & 2,36 & 6,21 & 9,13 \\
\hline \multicolumn{7}{|c|}{ Financial and economic activities } \\
\hline 9 & $\begin{array}{l}\text { Growth rate of income from income- } \\
\text { generating activities, } \%\end{array}$ & 49 & $-0,9$ & $-6,2$ & $-3,2$ & 1,1 \\
\hline 10 & $\begin{array}{l}\text { The ratio of the average salary of the } \\
\text { scientific pedagogical workers in an } \\
\text { educational organization (from all sources) } \\
\text { to the average salary in the economy of the } \\
\text { region, } \%\end{array}$ & 157,3 & 199,5 & 247,5 & 217,1 & 230,2 \\
\hline 11 & $\begin{array}{l}\text { The growth rate of income from research and } \\
\text { development work per research and teaching } \\
\text { staff, \% }\end{array}$ & 80,6 & 561,7 & 53,9 & $-17,6$ & 16,2 \\
\hline 12 & Rating of higher education organization & & & & & \\
\hline 13 & $\begin{array}{l}\text { Quality of financial management (index), } \\
\%\end{array}$ & 89,9 & 92,1 & 84,9 & 83,5 & 86,7 \\
\hline
\end{tabular}

As we can see from the results obtained, the indicator of the total area of educational and laboratory premises per student at USUE in 2016 has a value of $7.24 \mathrm{~m} 2$, and from the following year and for the entire study period, the indicator value is based on the level of 6.5 $\mathrm{m} 2$. As we noted earlier, during this period, there was an expansion of the blocks of directions for obtaining educational programs in law, food technology and bioengineering, which, in turn, attracted a large flow of new students on a contractual basis. Thus, the number of students increased, and the area of the premises remained the same. Based on the median 
value, we can determine that the indicator is consistently in the "yellow zone" for the entire study period and receives 5 points.

The value of the indicator of the number of copies of printed educational publications (including textbooks and teaching aids) out of the total number of registered library stock items per student (listed contingent) of the registered library stock items per student (listed contingent) in USUE for the entire study period is in the "green zone", there are no large deviations. For this indicator, 10 points are awarded for the entire period.

The number of personal computers per student (the given contingent) at USUE for the entire study period is as close as possible to the median value, which fixes the value of this indicator in the "yellow zone" and assigns 5 points.

The indicator of the proportion of NPS with the degree of candidate of Sciences, Doctor of Sciences in the total number of NPS also for the entire study period is in the "yellow zone".

The indicator of the growth rate of income from research and development work per one scientific and pedagogical employee at USUE for the entire study period (except for 2019) is assigned 15 points. The decline in the value of the indicator in 2019 is associated with a change in the system of calculating the performance indicators of higher education organizations, in this regard, 0 points are assigned.

The indicator of the growth rate of income from income-generating activities only in 2016 gets the maximum number of points-15. A noticeable jump was facilitated by a sharp influx of new students. From 2017 to 2019, the indicator shows a negative value, this is due to the high bar set in the previous year. In 2020, the value of the indicator will stabilize and get 3 points.

The value of the ratio of the average salary of the NPR in USUE (from all sources) to the average salary in the region's economy in 2016 is as close as possible to a high level, but gets 20 points. From 2017 until the end of the study period, the indicator value is at the highest level and receives 25 points.

The same thing can be noted regarding the quality of USUE financial management, the indicator for the entire study period is at the highest level and receives 20 points.

The number of USUE publications indexed in the information and analytical system of scientific citation Web of Science or Scopus and the number of citations published in the last 5 years indexed in the information and analytical system of scientific citation Web of Science or Scopus are consistently at the highest level, the indicators are 10 points. Deviations are observed only in 2016-2017, for which the indicator is assigned 5 points.

From 2016 to 2019, the average score of the Unified State Exam, which was received by applicants entering USUE, was located in the middle zone and received 10 points. In 2020, this indicator was 66.0 and was located at the highest level, scoring 15 points.

The indicator of the proportion of the number of foreign students studying under the bachelor's, specialist's, and master's programs of USUE in 2016-2017 has an extremely low value and receives 0 points. In 2018-2019, the indicator stabilized and was located in the middle zone, gaining 5 points, and in 2020, the indicator was located at the highest level, gaining 10 points.

Ranking of the best universities in Developing Europe and Central Asia. According to the presented rating, in 2016 and 2018, USUE was not included in the list and receives 0 points. In 2017, the situation is changing significantly, and USUE is located on the 251-300 place, receiving 4 points. After the stagnation of 2018, USUE was again included in the rating list in 2019 and 2020, placing at 301-350 place, gaining 2 points. 


\section{Conclusions}

Next, we need to calculate the total number of points scored, determine the economic security class in which USUE is located, and analyze whether conservative or creative factors have had a greater impact on this level and how.

Table 2. Final assessment of USUE economic Security for 2016-2020

\begin{tabular}{|c|c|c|c|c|c|c|}
\hline \multirow{2}{*}{ № } & \multirow{2}{*}{ Indicator } & \multicolumn{5}{|c|}{ Year } \\
\hline & & 2016 & 2017 & 2018 & 2019 & 2020 \\
\hline \multicolumn{7}{|c|}{ Scientific and technical support } \\
\hline 1 & $\begin{array}{l}\text { The total area of educational and laboratory facilities } \\
\text { per student (given contingent), } \mathrm{m} 2\end{array}$ & 5 & 5 & 5 & 5 & 5 \\
\hline 2 & $\begin{array}{l}\text { The number of copies of printed educational } \\
\text { publications (including textbooks and teaching aids) } \\
\text { out of the total number of items of the library fund that } \\
\text { are registered, per student (given contingent), units }\end{array}$ & 10 & 10 & 10 & 10 & 10 \\
\hline 3 & $\begin{array}{l}\text { The number of personal computers per student (given } \\
\text { contingent), units. }\end{array}$ & 5 & 5 & 5 & 5 & 5 \\
\hline 4 & $\begin{array}{l}\text { The number of publications of the organization } \\
\text { indexed in the information and analytical system of } \\
\text { scientific citation Web of Science or Scopus }\end{array}$ & 10 & 10 & 10 & 10 & 10 \\
\hline 5 & $\begin{array}{l}\text { The number of citations of publications published in } \\
\text { the last } 5 \text { years, indexed in the information and } \\
\text { analytical system of scientific citation Web of Science } \\
\text { or Scopus }\end{array}$ & 5 & 5 & 10 & 10 & 10 \\
\hline \multicolumn{7}{|c|}{ Intellectual and human resources } \\
\hline 6 & $\begin{array}{l}\text { Average USE score of students enrolled in full-time } \\
\text { study programs of higher education }\end{array}$ & 10 & 10 & 10 & 10 & 15 \\
\hline 7 & $\begin{array}{l}\text { The share of scientific and pedagogical workers with } \\
\text { the degree of Candidate of Sciences, Doctor of } \\
\text { Sciences in the total number of SPW, \% }\end{array}$ & 5 & 5 & 5 & 5 & 5 \\
\hline 8 & $\begin{array}{l}\text { The share of the number of foreign students enrolled } \\
\text { in bachelor's, specialist's, and master's programs, } \%\end{array}$ & 0 & 0 & 5 & 5 & 10 \\
\hline \multicolumn{7}{|c|}{ Financial and economic activities } \\
\hline 9 & $\begin{array}{l}\text { Growth rate of income from income-generating } \\
\text { activities, \% }\end{array}$ & 15 & 0 & 0 & 0 & 3 \\
\hline 10 & $\begin{array}{l}\text { The ratio of the average salary of the scientific } \\
\text { pedagogical workers in an educational organization } \\
\text { (from all sources) to the average salary in the } \\
\text { economy of the region, \% }\end{array}$ & 20 & 25 & 25 & 25 & 25 \\
\hline 11 & $\begin{array}{l}\text { The growth rate of income from research and } \\
\text { development work per research and teaching staff, \% }\end{array}$ & 15 & 15 & 15 & 0 & 15 \\
\hline 12 & USUE Rating & 0 & 4 & 0 & 2 & 2 \\
\hline 13 & Quality of financial management (index) & 20 & 20 & 20 & 20 & 20 \\
\hline \multicolumn{2}{|r|}{ Total number of points scored } & 115 & 114 & 120 & 107 & 135 \\
\hline \multicolumn{2}{|c|}{ Specific weight of points, $\%$} & 68,9 & 68,3 & 71,9 & 64,1 & 80,8 \\
\hline \multicolumn{2}{|c|}{ Economic security class } & $3-\mathrm{d}$ & $3-d$ & 2-nd & $3-d$ & 2-nd \\
\hline
\end{tabular}

Based on the final calculation of the points scored, we can observe that in 2016 USUE is located in the 3rd class of economic security according to the author's approach. The level of economic security of USUE was largely influenced by two creative factors: the share of the number of foreign students and the rating of the university.

In 2017, USUE also remains in the 3rd class of economic security. In this period of the study, both the creative factor (the share of the number of foreign students) and the 
conservative factor (the growth rate of income from income-generating activities) had an impact. We managed to cope with the creative factor, as USUE was in the ranking of universities.

The following year, USUE managed to climb a class higher, scoring $71.9 \%$ of the points. The influence of the creative factor (udel. weight chis. the number of students) decreased. At the same time, USUE again did not get into the rating of universities, but was able to increase the number of citations of publications in international databases, reducing the influence of this creative factor to a minimum.

In 2019, USUE again fell into the 3rd class of economic security. This is due to the fact that points were lost for the indicator of the growth rate of income from R \& D. The influence of this creative factor has increased, as we noted earlier, due to changes in the system of calculating the performance indicators of higher education organizations. But, nevertheless, USUE again got into the rating of the best universities.

In the last year of the study period, USUE rose to the 2 nd class of economic security. At the same time, USUE managed to minimize the influence of the creative factor (the specific weight of the chis. inostr. students) to a minimum. The indicator of the income growth rate has normalized. In the same year, the average score of the Unified State Exam admitted to USUE was raised, which minimized the influence of this conservative factor. USUE has consolidated its position in the ranking among universities.

Thus, we can conclude that throughout the entire period of the study, USUE's economic security was largely influenced by creative factors. Conservative factors also have a big impact on the level of economic security, but in 2020, USUE minimized the influence of most creative and conservative factors.

\section{References}

1. T.A. Makhmutov, How the coronavirus will change our lives in 2021: forecasts for the future, https://ach.gov.ru/

2. Higher School of Economics "Five challenges for universities - five opinions of international experts", https://ioe.hse.ru/

3. E.B. Dvoryadkina, Ya. P. Silin, N.V. Novikova, Economic security, 194 (2016)

4. International Monetary Fund, COVID-19 is a serious threat to aid to education recovery, Policy Paper, https://unesdoc.unesco.org/

5. Analytical report of the Accounts Chamber of the Russian Federation "Coronavirus epidemic: impact on education", https://ach.gov.ru/

6. Rating agency QS (Quacquarelli Symonds), https://www.topuniversities.com/

7. A.E. Sudakova, Science and Education Perspectives, 45(3), 544 (2020)

8. S.D. Bodrunov, Noonomics: the trajectory of global transformation (2020)

9. E.N. Levashov, Symbol of Science, 2-2 (2016)

10. I.M. Ilyinsky, Knowledge. Understanding. Skill, 2, 3 (2013)

11. M.A. Vinokurov, News of the Irkutsk State Economic Academy, 6, 5 (2013)

12. M.P. Astafieva, O.A. Zyateva, I.V. Peshkova, E.A. Pitukhin, University Management: Practice and Analysis, 4, 4 (2015)

13. Rating agency QS (Quacquarelli Symonds), https://www.topuniversities.com/

14. E.V. Mikhailin, A.V. Grachev, Legal science and practice: Bulletin of the Nizhny Novgorod Academy of the Ministry of Internal Affairs of Russia, 2(11) (2009) 
15. A.V. Taraskina, S.N. Obukhova, S.V. Zolotova, Economic analysis: theory and practice, 16(4), 726 (2017) 